\title{
Structural Transformation of Staff Educational System for Nanoindustry
}

\author{
Elena N. Desyatirikova \\ Voronezh State Technical University \\ Voronezh, Russia \\ science2000@ya.ru
}

\author{
Yu. V. Khripunov \\ Orel State University \\ Orel, Russia \\ phyrexia@yandex.ru
}

\author{
Vladimir E. Mager \\ Peter the Great St. Petersburg State Polytechnic University \\ St. Petersburg, Russia \\ mv@qmd.spbstu.ru
}

\begin{abstract}
The necessity of transforming the training system in the development of high-tech industries is shown. The decisive role of the state in the structural transformation of the training system for high-tech industries is established on the example of the nanoindustry. A number of solutions to provide personnel for nanoindustries developed by the RUSNANO Group are presented.
\end{abstract}

Keywords - nanotechnology; online education; educational system effectiveness

\section{INTRODUCTION}

Creating the conditions for economic growth and productivity based on new materials and technologies is a common goal of economic development. Along with the increasing use of technological innovations in the economy, it is necessary to focus on structural transformations in the training management system for the regional economy during the digital revolution. And especially for those sectors of the economy in which a country or region has a comparative advantage. One of such high-tech industries is the nanoindustry, in which our country has both a serious fundamental backlog and substantial practical experience.

Nanomaterials and nanotechnologies are relatively new scientific and production content that required special attention at the turn of the 2000s. This focus was mainly on the investment aspects of developing new materials; with unpredictable risks of their use associated with nanoparticles and nanocompounds; with the lack of the possibility of creating a universal regulatory framework and standards for the nanoindustry. Thus, the reaction of society to the development of nanotechnology (including investment, the creation of legal norms and recommendations) is a marker of the state of the digital economy, which determines how to solve other similar problems.

Like any new activity, the development of the nanoindustry required structural changes in the training management system for the corresponding scientific and production sectors of the economy. Obviously, without a systematic approach to managing the training of relevant personnel, our country will not only not solve the problem of the transition to innovative development, but will further consolidate its growing lag behind the leading world economies. Until now, the lack of a holistic concept of the state system for the development of human resources and the training of scientific personnel, based on the presentation of this system as a complex and multifactorial management object, puts this problem in a number of particularly acute

The subject of this work is an integrated training management system for high-tech industries based on the example of the nanoindustry. At present, there is no analysis of such an object of management, nor are the processes of development of modern methods and mechanisms for managing it observed; as a result, there is a lack of a concept, methodology and conceptual practical development of a system for managing the development of human resources for targeted impact in the high-tech sector of the economy in order to obtain given characteristics. The current management is characterized by the absence of a goal-setting education system in the field of nanotechnology, the lack of feedback from the professional community, and, as a result, the small influence of the digital society environment on its structural component, namely, the educational cluster.

\section{Problems AREA OF ACTIVITY}

The current state of the educational component of the innovative development of the country is characterized by insufficient development of a systemic worldview in the management of the training system. For the nanoindustry, this, in particular, is manifested in the following.

- There is no single stratified management system for training personnel in the field of vocational education, which does not contribute to the development of the personnel potential of the industry. 
- The education system is quite closed (both in the industry. And in the regional aspect). This, on the one hand, is due to the uneven distribution of the production base, geographically distant from educational organizations. On the other hand, this is a reflection of the fact that the top management of industrial enterprises is not able to qualitatively form an order for educational organizations for promising labor resources.

- Low competitiveness of higher education, as well as secondary professional level, due to the insufficient level of use of advanced scientific developments in the educational process. This is a consequence of the inertia of the teaching staff's thinking, reflecting their general "aging", lower social status, and limited mobility.

Thus, one of the main tasks of creating an innovative economy, the economy of new materials and new technologies, is the task of providing it with new personnel at all stages of its implementation. This means that it is necessary to generate teaching staff to create human resources for hightech production. This process of parallel reproduction of the personnel potential of a high-tech digital society is proposed to be solved within the framework of portfolio educational technologies using the example of project activities in the nanoindustry.

The general goal of the management system for developing the human resources potential of the nanoindustry is to integrate all levels of education, science and high technology production in order to prepare competitive scientific and production personnel at the level of world qualification requirements and their effective use for the development of the economy of a digital society, including solving social problems, strengthening defense and security, outstripping the development of priority research and new technology-oriented and the knowledge economy, while maintaining continuity of scientific and pedagogical schools.

The implementation of portfolio technologies for the reproduction of human resources in high-tech industries, such as the nanoindustry, should be carried out in the vector field of the following factors $(\boldsymbol{F})$ according to the classical principles $(\boldsymbol{P})$ of System Theory.

F1 - conducting fundamental, search and applied research of interdisciplinary knowledge. $\boldsymbol{P 1}$ - the principle of integrity and completeness is manifested in the completeness of the knowledge involved to achieve the goals.

$\boldsymbol{F 2}$ - interaction with the environment for the development of competitive innovative projects both at the national and interstate levels in a given industry. $\boldsymbol{P} 2$ - the principle of scientific and economic feasibility involves the use of all available resources to achieve the planned result in a given time interval with minimal resource costs.

F3 - close cooperation with the manufacturing sector, as with the end user of the educational product; with the prospect of developing this area to the level of the customer of the education system. $\boldsymbol{P 3}$ - the principle of social responsibility means making decisions in the field of managing the personnel potential of the industry based on social priorities.

\section{CONCEPT OF STRUCTURAL TRANSFORMATIONS OF THE MANAGEMENT EDUCATIONAL SYSTEM}

From the point of view of the general theory of systems, the development of the management system for the staffing of a high-tech industry over time is the process of increasing its organization in achieving the set goals for its functioning. Moreover, these goals themselves are dynamic, changing depending on the conditions in which the control system operates. The development of this system is naturally manifested by an increase in the amount of information $(I)$ circulating in the system and accumulating in its thesauruses. The increase in the information capacity of the control system is aimed at increasing the efficiency, and therefore, at reducing the energy $(E)$ and labor $(T)$ costs, reducing the regression indicators, decreasing the entropy $(H)$ (increasing the degree of organization of the system):

$$
\left\{\frac{d I}{d t}>0 ; \frac{d E}{d t}>0 ; \frac{d T}{d t}>0 ; \frac{d H}{d t}<0\right\}
$$

The fulfillment of this condition is an indicator of the successful development of the personnel management system. We take into account the dynamic nature of the state of the personnel management system (Educational Center) in the following model. Denote:

$D_{t}-$ simulation step (time interval from time $t_{i}$ to time $t_{j}$ );

$\mathrm{N}_{\mathrm{ti}}$ and $\mathrm{N}_{\mathrm{tj}}-$ the number of students at time $\mathrm{t}_{\mathrm{i}}$ and $\mathrm{t}_{\mathrm{j}}$;

$\mathrm{PB}_{\mathrm{Dt}}$ is the rate of the stream that sets the input flow of students to the Learning Center during the interval $D_{t}$ (from time $t_{i}$ to time $t_{j}$ );

$\mathrm{OT}_{\mathrm{Dt}}$ is the rate of the stream that defines the output stream of students who have not completed training and have not received the appropriate competencies during the interval $D_{t}$ (from time $t_{i}$ to time $t_{j}$ );

$\mathrm{OB}_{\mathrm{Dt}}$ is the rate of the flow that sets the graduates from the Learning Center during the interval $D_{t}$ (from time $t_{i}$ to time $t_{j}$ ).

Then the number of students in the Center is described by the following relation

$$
N_{t_{j}}=N_{t_{i}}+D_{t} \cdot\left(P B_{D_{t}}-O T_{D_{t}}-O B_{D_{t}}\right)
$$

The effectiveness of the Educational Center from the point of view of the employer:

$$
E_{t_{j}}^{B}=\frac{O B_{D_{t}}}{P B_{D_{t}}+O T_{D_{t}}} .
$$

The efficiency from the point of view of the Educational Center:

$$
E_{t_{j}}^{E}=\frac{N_{t_{i}}-O T_{D_{t}}}{N_{t_{i}}}
$$


Then the objective function of the Educational Center:

$$
z\left(E^{B}\right) \rightarrow \max .
$$

The indicated flow rates in the state model of the personnel management system can be described taking into account the importance of various parameters:

- orientation of the training system on the result,

- concentration of resources and funds at growth points (about 50 supporting organizations, including the sites of qualification assessment centers in the nanotechnology industry - Universities: FEFU, NSTU, KNITU, LETI, SPbGTI (TU) and Voronezh State University),

- a networked organization of relationships between training institutions (including early career guidance on the basis of the Sirius Educational Center, the Quantorium technology parks, the means of the Stemford online educational platform, etc. [1, 2, 3]).

Table 1 presents the types of functions of the flow trend model in the training system for the nanotechnology industry, depending on the expected changes in the importance of its parameters.

TABLE I. FLOW TREND MODELS

\begin{tabular}{|c|c|c|}
\hline \# & $\begin{array}{l}\text { Intensity importance } \\
\text { dependent on time }\end{array}$ & $\begin{array}{l}\text { Waiting for the dynamics of } \\
\text { judgments }\end{array}$ \\
\hline 1 & $y(t)=\alpha$ & Relative weight does not change \\
\hline 2 & $y(t)=a_{1}(t)+a_{2}$ & $\begin{array}{l}\text { Constant increase in one type of } \\
\text { activity in comparison with another }\end{array}$ \\
\hline 3 & $y(t)=b_{1} \log (t+1)+b_{0}$ & $\begin{array}{l}\text { Fast increase (decrease) followed by } \\
\text { a slow increase (decrease) }\end{array}$ \\
\hline 4 & $y(t)=c_{1} \exp \left(c_{2} t\right)+c_{3}$ & $\begin{array}{l}\text { Slow increase (decrease) followed by } \\
\text { rapid increase (decrease) }\end{array}$ \\
\hline 5 & $y(t)=d_{2} t^{2}+d_{1} t+d_{0}$ & $\begin{array}{l}\text { Increase (decrease) to maximum } \\
\text { (minimum) and then decrease } \\
\text { (increase) }\end{array}$ \\
\hline 6 & $y(t)=e_{1} t^{n}+\sin \left(t+e_{2}\right)+e_{3}$ & $\begin{array}{l}\text { Oscillation with increasing } \\
\text { (decreasing) amplitude as a function } \\
\text { of } n\end{array}$ \\
\hline
\end{tabular}

The greatest increase in the effectiveness of $\Delta E^{B}$ application of a given educational technology is observed at the stage of its development (see Fig. 1).

At an early stage in the development of educational technology, its effectiveness is low due to insufficient practical development of a new educational technology. Also, the effectiveness of its application tends to attenuate even with the "exhaustion" of the current educational technology.

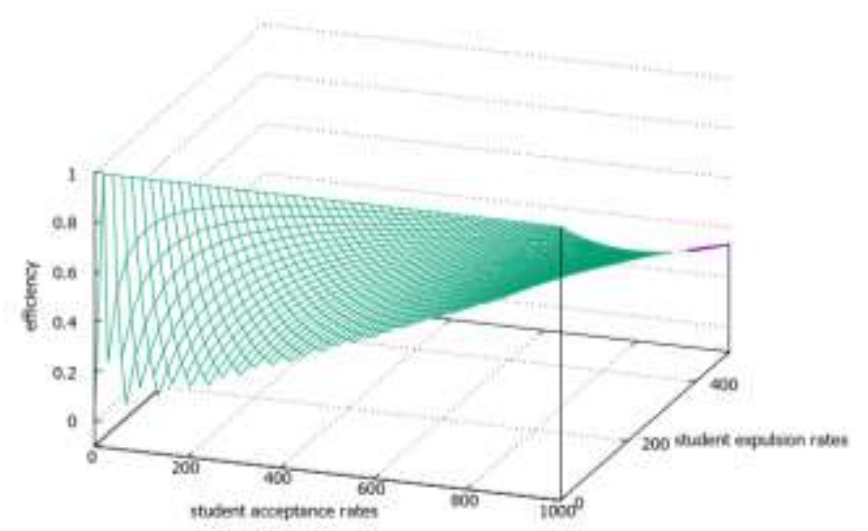

Fig. 1. The effectiveness of the Educational Center for flow models No. 2 (according to Table 1)

At the same time, the "dying" technology manifests its protective properties in the creation of control systems of structural elements that are ultimate in power or in size. Such "gigantomania" at the limit of the possibilities of obsolete educational technology, however, is not cost-effective either in terms of building management competence or in terms of practical implementation.

Here we are dealing not just with a regularity of an economic nature, but with the fundamental universal law of decreasing entropy in closed systems with irreversible processes occurring in them. Obviously, any socio-economic system of any dimension can be specialized just like this type of system. This law is implemented in all cyclically developing systems and only for large periods of time, which is true, for example, for long-wave economic cycles (such as Kondratyev's cycle [4]).

Thus, in the role of a closed system, we can consider the technological structure of the economy. The information technology for managing a large closed-loop system is improved in every specific Kondratyev's cycle on the basis of an invariable technological principle. However, with the achievement of a certain level of development of the management system, the cost of its new structural changes grows in proportion to the large degrees of growth in its effectiveness. Therefore, the profit from additional capital investments in the reform of the management system under the same other business conditions will be less than the profit from the previous investment of the same amount of capital in solving the same problem. This means that at the end of each economic cycle of the development of society, a structural restructuring of the economic management systems at the macro level is necessary, the priority of which is to support new knowledge-intensive sectors instead of traditional capitalintensive branches of the economy.

As the training management system approaches the maximum level of development, its effectiveness indicator becomes insensitive to changing employer demands, which makes the system closed and, according to the above law of increasing entropy, makes it unprofitable [5]. 
Nevertheless, the transition to the next technological level of economic development is a consequence of reaching the ultimate level of development. This shows the dialectic and source of development of the economic life of society: it makes sense to continuously develop the high-tech sector of the economy, despite the fact that at some stage the costs of its fundamental and production support will exceed the current effect of its use. Therefore, in most cases, a market (spontaneous) balancing of supply and demand for high-tech resources is impossible. This means that objectively there is a task of state regulation of knowledge-intensive industries. This problem is solved by the creation of mechanisms of continuous, purposeful and at times tough state intervention in the economic life of society. Such "pressure" is strategically justified and pays off at the following technological levels of economic development. In the field of nanotechnology, the relevant mechanisms took place within RUSNANO Group.

\section{RUSNANO GROUP STAFF SOLUTIONS}

Obviously, the task of training personnel for the nanotechnology industry requires ensuring the acquisition of such competencies that will allow one to operate both in the field of intellectual content of the fundamental knowledge of nanotechnology and in the field of project management at the level of their investment, technical and technological components. The tool for quick response to the lack of competencies of specialists in the nanotech is the educational projects of the RUSNANO Group Fund for Infrastructure Educational Programs (for example, [1]).

At present, the scientific and pedagogical community of 60 universities and 10 scientific organizations with the support of the Foundation have developed and are implementing 182 educational programs. Based on the materials of these programs, 80,000 specialists of enterprises and students were trained in nanotech specialties, $78 \%$ of whom work in the field of innovation. 4 leading universities (MIPT, MISiS, NRNU MEPhI, RANEPA) and 20 companies (OCSiAl, MapperLithography, InEnergy, R-Sensors, etc.) train specialists in the field of technological entrepreneurship with industry specifics.

The development of technologies, production processes and, therefore, personnel requirements required the systematization of documents and qualifications that industry workers need. In the National Council under the President of the Russian Federation for Professional Qualifications, 63 professional standards have been developed and approved. Manufacturers, as well as representatives of the scientific and educational community, have the opportunity to participate in the development of professional standards and thereby influence the creation of personnel infrastructure for a new industry. The Council's activity plan is publicly available on spknano.ru.

The RUSNANO Group school league has been created, which includes more than a thousand schools and twenty resource centers in which the Foundation supports the development of science education, conducting, together with Moscow State University and the Agency, strategic initiatives for olympiads, scientific and educational and career guidance programs. Digital learning technologies have been developed for this target audience. The basis of their functionality is providing access to new knowledge and, first of all, highquality content in the field of advanced technologies by means of educational platforms edunano.ru and stemford.org [6]. They contain special courses for wide audiences, and especially for schoolchildren - as a promising personnel resource. The Talent and Success Educational Foundation, in partnership with and with the support of the Fund for Infrastructure and Educational Programs (RUSNANO Group), developed and implemented a special model program for continuing education for children, focused on the study of the natural sciences and the foundations of nanotechnology, developed. Program content and modules are freely available on the website https://sochisirius.ru/news/2985. Projects and programs focused on the school audience have the goal of making the student interested in acquiring competencies in demand in the nanoindustry. The model of the technopark associated with the method of organizing the innovation process - the transformation of new knowledge into a new product, is called upon to become the cultural source of such competencies.

\section{CONCLUSION}

Digitalization of the economy is associated with innovations in high-tech industries, which determines the structural restructuring of the training system for these industries. It is fundamental to take into account the universal law of non-decreasing entropy in the development of socioeconomic systems. Using the example of nanoindustry, the necessity of state regulation of the educational system is proved. A number of decisions on providing personnel for the nanoindustry developed by the RUSNANO Group are presented. The package of solutions is distinguished by the integration of various educational technologies into a single cross-age technology for training personnel for nanotechnology.

\section{REFERENCES}

[1] RUSNANO Group. Available at https://en.rusnano.com/about/fiep\#/education (accessed 12 April 2019)

[2] Stemford logo. Available at: https://stemford.org/enano (accessed 20 April 2019)

[3] Liyanagunawardena T.R., Adams A.A., Williams S.A. MOOCs: A Systematic Study of the Published Literature 2008-2012 // The International Review of Research in Open and Distance Learning. 2013. V. 14, No. 3. P. 202-227.

[4] Snyder Michael "If Economic Cycle Theorists Are Correct, 2015 To 2020 Will Be Pure Hell For The United States". The Economiccollapseblog.com. Retrieved December 1, 2016.

[5] Loginova A.V., Algazinov E.K., Garshina V.V., Sychev A.V., Desyatirikova E.N., Smoljyaninov A.V., "Collaboration with Employers in IT Training," 2017 IEEE VI Forum Strategic Partnership of Universities and Enterprises of Hi-Tech Branches (Science. Education. Innovations) (SPUE), St. Petersburg, 2017, pp. 88-91. doi: 10.1109/IVForum.2017.

[6] Desyatirikova E.N., Myshovskaya L.V., Lapshina K.N., Khripunov $\mathrm{Yu}$.V. "Automatic Quality Control of Processes in the Online Educational Environment" in Proc. IT\&QM\&IS 2019; Sochi; Russian Federation; 23-27 September 2019, Publisher: IEEE, doi: 978-1-72812595-4/19/\$31.00 (C)2019 IEEE 